\title{
Correction to: The Police Officer Perception Project (POPP): An experimental evaluation of factors that impact perceptions of the police
}

\author{
Rylan Simpson ${ }^{1}$
}

Published online: 16 November 2017

(C) Springer Science+Business Media B.V., part of Springer Nature 2017

Correction to: J Exp Criminol (2017) 13:393-415

https://doi.org/10.1007/s11292-017-9292-4

As part of the production process, the numerical values for negative and positive police contact in Table 1 were erroneously swapped. The corrected values should be:

- Negative: $21(7 \%)$

- Positive: $62(20 \%)$

The online version of the original article can be found at https://doi.org/10.1007/s11292-017-9292-4.

\section{Rylan Simpson}

simpson@uci.edu

1 Department of Criminology, Law and Society, University of California, Irvine, 2340 Social Ecology II, Irvine, CA 92697, USA 